\title{
Coordinated Hunting by Cuban Boas
}

\begin{abstract}
Vladimir Dinets ${ }^{1, *}$
${ }^{1}$ University of Tennessee, Knoxville, TN

*Corresponding author (Email: dinets@gmail.com)

Citation - Dinets, V. (2017). Coordinated hunting by Cuban boas. Animal Behavior and Cognition, 4(1), $24-29$. https://doi.org/10.12966/abc.02.02.2017

Abstract - Coordinated hunting, in which individual predators relate in time and space to each other's actions, is uncommon in animals, and is often difficult to distinguish from simply hunting in non-coordinated groups, which is much more common. The author tested if Cuban boas (Chilabothrus angulifer) hunting bats in cave passages take into account other boas' positions when choosing hunting sites, and whether their choices increase hunting efficiency. Snakes arriving to the hunting area were significantly more likely to position themselves in the part of the passage where other snakes were already present, forming a "fence" across the passage and thus more effectively blocking the flight path of the prey, significantly increasing hunting efficiency. This is the first study to test for coordination between hunting reptiles, rather than assume such coordination based on perceived complexity of hunting behavior.
\end{abstract}

Keywords - Boidae, Chilabothrus angulifer, Cooperative hunting, Cuba, Predation, Social behavior

Coordinated hunting, in which individual predators relate in time and space to each other's actions, is uncommon but widespread in animals (Bailey, Myatt, \& Wilson, 2012). Among vertebrates, coordinated hunting is presently known with certainty in hominid primates (Boesch \& Boesch, 1989; Stiner, Barkai, \& Gopher, 2009), a few carnivores (Bailey et al., 2012; Creel \& Creel, 1995; Eaton, 2009; Mech, 2007; Stander, 1992), cetaceans (Gazda, Connor, Edgar, \& Cox, 2005; Smith, Siniff, Reichle, \& Stone, 1981), two species of raptors (Bednarz, 1988; Leonardi, 1999), two species of corvids (Bowman, 2003; Yosef \& Yosef, 2010), a few species of fish (Bshary, Hohner, Ait-El-Djoudi, \& Fricke, 2006; Herbert-Read et al., 2016; Lönnstedt, Ferrari, \& Chivers, 2014), crocodilians (Dinets, 2015), and monitor lizards (James \& Fox, 2007; Pitman, 1931). As for invertebrates, coordination has never been demonstrated in any of the taxa known to hunt in groups (see Hyodo, Himuro, \& Fujisaki, 2014), although coordination in post-hunt transportation of prey is known in ants (Lioni, Sauwens, Theraulaz, \& Deneubourg, 2001).

Although coordinated hunting is likely more widespread than is currently known, it is often difficult to distinguish from hunting in non-coordinated groups, which is common (both types are often indiscriminately called "cooperative hunting"). To confirm that coordination does occur, one has to demonstrate that the predators take each other's positions and/or actions into account, rather than simply gather in the same area due to following the same stimuli. When proving this is impossible or impractical, coordination is often assumed based on perceived complexity of hunting patterns, such as in all reported cases of apparent coordination in reptiles, where some of the hunters drive the prey towards others, distract prey to facilitate the attack by others, or force prey into a compact area and then take turns attacking it (Cott, 1961; Dinets, 2015; Horn, 1999; James \& Fox, 2007; Pitman, 1931). 
Coordinated hunting requires higher behavioral complexity because each animal has to take other hunters' actions into account (Bernard, André, \& Bredeche, 2016) and is usually implied to increase the effectiveness of the hunt, but this is not necessarily true: for example, studies of gray wolves (Canis lupus) have shown that coordinated hunting in large packs does not necessarily increase food intake per individual and might have social functions (Mech \& Boitani, 2003). There are only a handful of species for which coordinated hunting has been shown to increase food intake per individual (e.g., Bowen, 1981; Herbert-Read et al., 2016; Lönnstedt et al., 2014).

Snakes sometimes congregate at hunting locations (Doody, Burghardt, \& Dinets, in press; Nedyalkov, 1967), but it is unknown if they coordinate their hunting behavior with other participants. Puerto Rican (Chilabothrus inornatus) and Cuban (C. angulifer) boas are known to form aggregations in cave passages when hunting bats are flying in or out of roosts (Hardy, 1957; Rodriguez \& Reagan, 1984). In the present study the author tested if Cuban boas hunting bats in a cave take into account other boas' positions in a way that allows them to most effectively block the bats' flight path and maximize the effectiveness of hunting.

\section{Method}

\section{Materials and Procedure}

For eight days in March 2016, the author observed Cuban boas hunting Jamaican fruit bats (Artibeus jamaicensis) in a sinkhole cave in Desembarco del Granma National Park, Cuba. The cave was inhabited by nine boas, easily recognizable by individual markings (Figure 1), ranging from 110 to 210 $\mathrm{cm}$ long (sizes estimated visually). The passage from the roosts to the cave entrance was $1.8-2.5 \mathrm{~m}$ wide, up to $2.2 \mathrm{~m}$ high, and $12 \mathrm{~m}$ long (measured by tape measure), with the ceiling dotted with numerous small pits providing ample support for climbing boas. During the day and on moonlit nights, some visible (to a human observer) light from the entrance penetrated the entire length of the passage.

After sunset and before dawn, some of the boas entered the passage that connected the roosting chamber with the entrance chamber, and hunted by suspending themselves from the ceiling and grabbing passing bats.

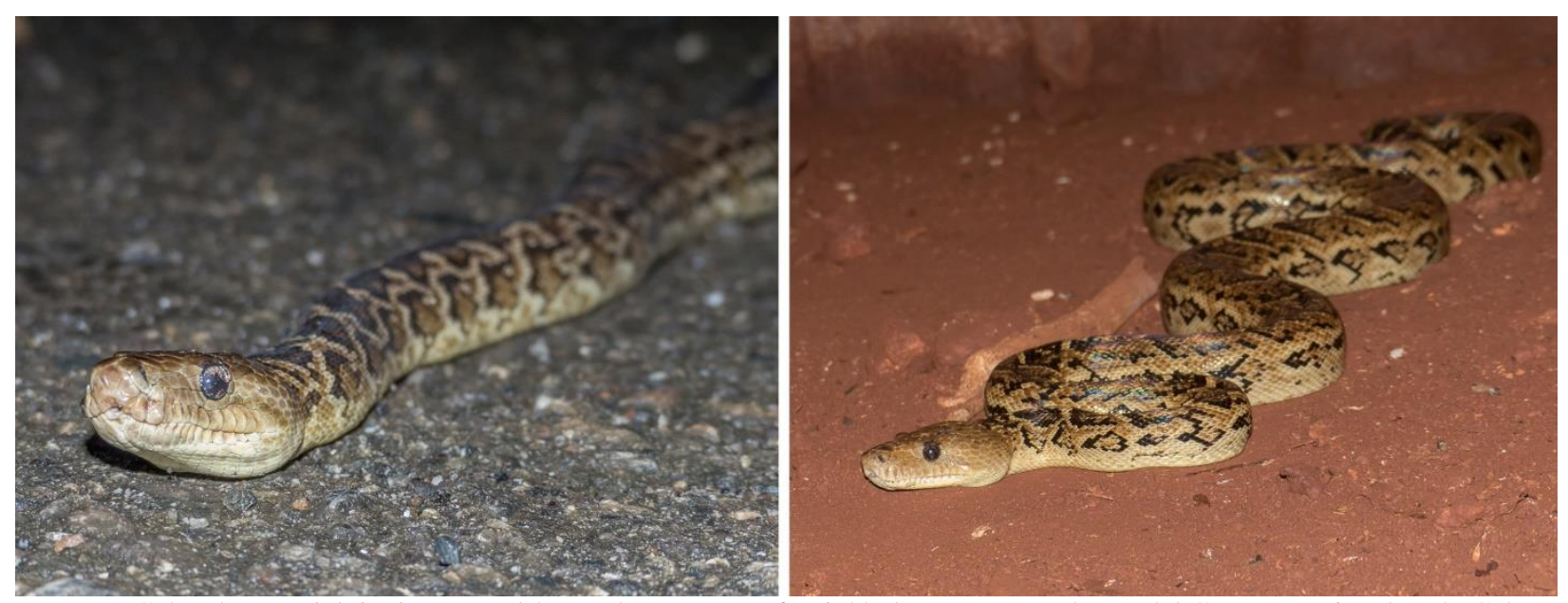

Figure 1. Cuban boas (Chilabothrus angulifer) at the entrance of a sinkhole cave, Desembarco del Granma National Park, Cuba. Note the high variability of individual markings. Photography was not used inside the cave to avoid disturbing boas and bats.

All visual observations were conducted using red light (Energizer 5 LED headlamp), laser distance meter (Johnston), and 8x42 binoculars (Nikon Aculon A211). The observations were started as soon as a boa was seen entering the passage, and ended when all boas left it. The author divided the passage into 24 longitudinal sections $50 \mathrm{~cm}$ long (using a measuring tape), each marked with two 
numbered rocks positioned at the base of the passage walls. Then he recorded which sections were chosen by boas as they arrived to the passage and climbed to the ceiling to hunt. An exact binomial probability test was used to assess whether the second and the third boas to arrive (if present) were more likely to position themselves in the same segment as the first one. When three boas were present, the choices by the second and the third boas were treated as independent events. Only some of the eight segments closest to the cave entrance were chosen during evening hunts, and only some of the 11 segments closest to the roost chamber were chosen during pre-dawn hunts (see Results), so these two sets of hunts were analyzed separately with $n=8$ and $n=11$, respectively. To test for individual preferences, all segment choices made by each individual boa were recorded.

The author also recorded the times between the beginning of the bat flight (defined as having five or more bats simultaneously in flight within the observer's field of view) and each prey capture (or, if the hunt failed, the departure of the boa from the passage ceiling). To test if the times from the beginning of bat flight to the captures were significantly different between hunts with different numbers of boas present, the author used lme4 package in R (Pinheiro, Bates, DebRoy, Sarkar, \& R Core Team, 2016) to perform GLMM analysis, with the number of participating boas as a fixed effect and boa ID as a random effect. P-values were obtained by likelihood ratio tests of the full model with the effect in question against the model without the effect in question. Failed hunts were dropped from this analysis.

Fisher Exact Tests, 2-tailed, were used to find if there was a difference in hunt failure probability between one-boa and multiple-boas hunts, and a 2-tailed $t$-test to compare average food intake per boa between solitary and group hunts (in these cases using GLMM would be unnecessary since food intake per snake was always " 1 " during successful hunts (see Results) and the two observed failed hunts were not by the same boas, so individual variation in hunting success between boas could not play a measurable role).

\section{Results}

Every day during the observation period, most or all boas spent the daylight hours around the cave entrance, and most of the night in the chamber where a few hundred bats roosted during the day (Figure 2A), possibly because that chamber was the warmest part of the cave at night, and/or because dead bats could occasionally be found there.

In the evening some of the boas would arrive to the passage $10-30 \mathrm{~min}$ before the beginning of the bat flight and assume hunting positions on the ceiling. In pre-dawn hours, they arrived $20-60$ min before the onset of the mass return of the bats. As there were two hunting periods per day, a total of 16 hunts was observed. The maximum number of boas observed hunting simultaneously was three. If multiple boas were present, they positioned themselves in the same part of the passage, forming a barrier (Figure 2B).

Of 16 observed hunting events, a single boa was present in three cases (three different individuals), two boas were present in nine cases, and three boas were present in four cases. In 12 of 13 cases when more than one boa participated in the hunt, the second snake to arrive chose the same segment as the first one (in the one remaining case it was an adjacent segment). In all four cases when three boas participated, the third snake chose the same segment as the other two. This preference was significant $(p<$ 0.001) for both evening and pre-dawn hunts.

An alternative explanation for the boas choosing the same part of the passage would be that they had similar individual preferences. Indeed, a preference for segments near passage ends was obvious: six of the eight segments closest to the cave entrance were the only ones chosen during evening hunts, and seven of the 11 segments closest to the roost chamber were the only ones chosen during pre-dawn hunts. That preference for segments near the ends of the passage was excluded as an alternative explanation by using only these segments as possible outcomes during the analysis, as noted in the Method section. However, no individual boa ever used the same segment more than once, so the tendency to use the same segment as other boas was not due to similar individual preferences for particular segments. 


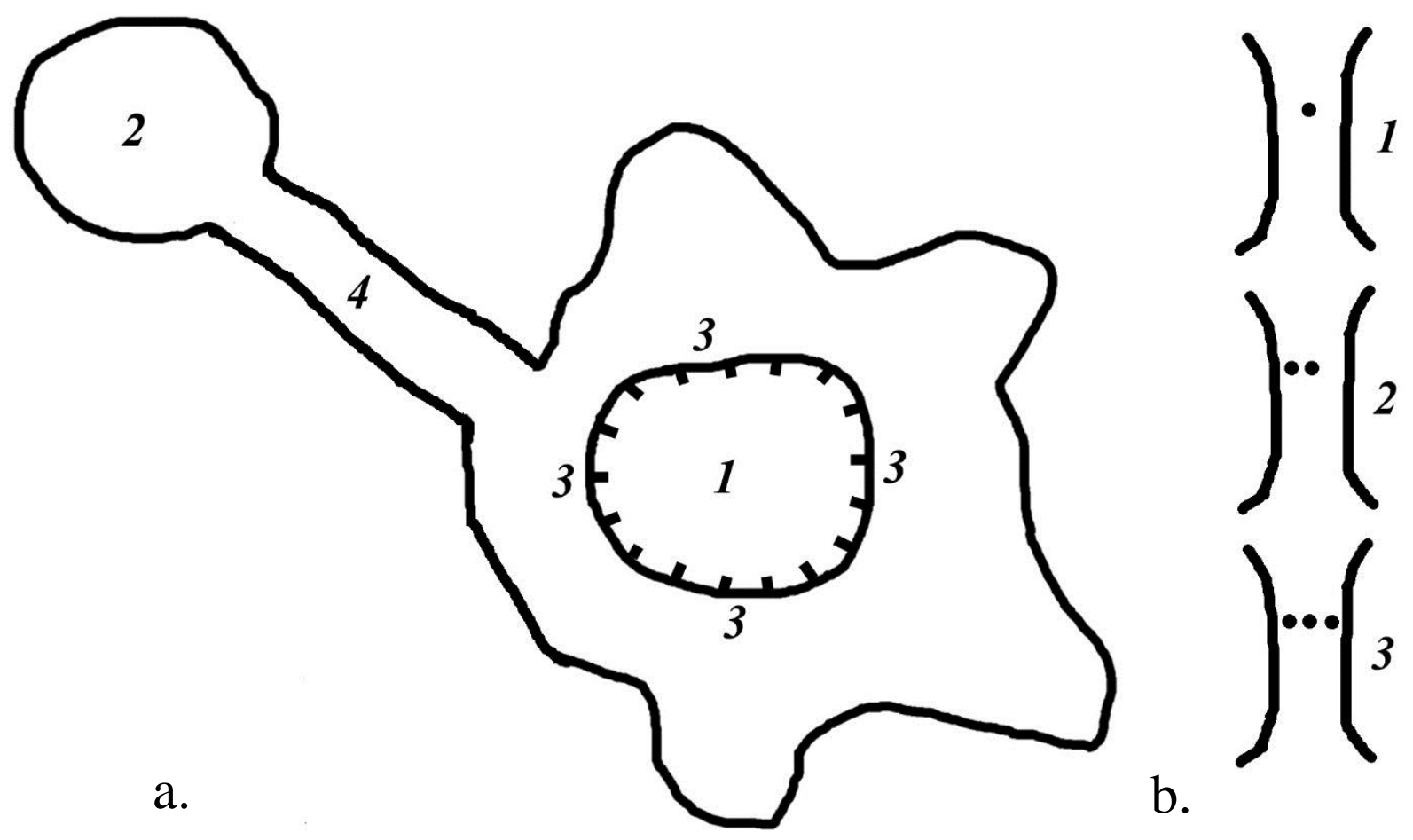

Figure 2. Schematic map of the study cave in Desembarco del Granma National Park, Cuba. (a) One vertical entrance, two bat roosts, three daytime boa basking areas, four connecting passages where boas hunt bats. (b) A typical sequence (1 - 3) of hunting site choice by boas arriving for bat hunting.

When a bat was captured, the boa consumed it and left the passage, so no more than one bat was caught by each boa during each hunt. In all hunting attempts by all snakes $(N=33)$ except two, a bat was captured. Both unsuccessful hunts happened when there was only one boa present. In these cases, the boas abandoned their hunting positions after 22 and $29 \mathrm{~min}$ (after the peak intensity of bat flight but before the number of passing bats dropped to less than five bats simultaneously in the observer's field of view). The mean time from the onset of bat flight to prey capture was 19 min when there was one boa present $(N=1) ; 10.2 \mathrm{~min}$ when there were two $(N=18)$, and $6.7 \mathrm{~min}$ when there were three $(N=12)$. The number of boas present had a significant effect on the time to capture (slope estimate -6.442 , error 0.8115 , $t(30)=-7.94, \quad p<0.01)$.

Despite the small sample size for hunts by just one boa, such hunts were significantly more likely to result in failure $(p<0.01)$. Average food intake was 0.33 bats per boa during individual hunts, and 1 bat per boa during group hunts $(t(15)=9.81, p<0.001)$.

Visual observations suggested that most bats were able to avoid flying near boas when there were one or two boas present, but with three boas present the bats had to fly either within striking distance from one of them (often colliding with the boas), or very low above the passage floor. Confirming these differences in bat flight patterns would require video recordings with an infrared camera.

\section{Discussion}

The present study suggests that boas take the positions of other individuals into account when choosing the hunting location. They position themselves in a way that allows them to form a barrier 
across a cave passage. This significantly improves the effectiveness of the hunt, apparently because they can most effectively block the prey's flight path and easily intercept passing bats.

This is the first scientifically documented case of coordinated hunting by snakes. It is also the first study on reptiles to statistically test for coordination between hunters and to show that coordination increases hunting success.

Studies of social behavior in reptiles in the wild are few, the prevalence of such behavior appears to be highly underestimated, and many important observations remain unpublished (Doody, Burghardt, \& Dinets, 2013). There are videos of a number of snake species hunting in large groups, for example, of banded sea kraits (Laticauda colubrina) hunting in apparent coordination between themselves and with two species of predatory fish (see http://www.bbc.co.uk/programmes/p0038t09), and of Galapagos racers (Philodryas biserialis) hunting iguana hatchlings (see http://www.bbc.com/earth/story/20161114-fromplanet-earth-ii-a-baby-iguana-is-chased-by-snakes), but these observations have never been published scientifically. It is possible that boas are not unique among snakes, and that coordinated hunting is not particularly rare. This possibility suggests that at least some snakes are not the "solitary animals" they are commonly considered to be, and that they are capable of high behavioral complexity required for such hunting (Bernard et al., 2016).

\section{Acknowledgements}

I thank Mico Balboa and Sergei Kolenov for help with various aspects of field research, Boris Krasnov for help with statistics, and the anonymous reviewers for extensive editorial input.

\section{References}

Bailey, I., Myatt, J. P., \& Wilson, A. M. (2012). Group hunting within the Carnivora: Physiological, cognitive and environmental influences on strategy and cooperation. Behavioral Ecology and Sociobiology, 67, 1-17.

Bednarz, J. C. (1988). Cooperative hunting in Harris' hawks (Parabuteo unicinctus). Science, 39, 1525-61527.

Bernard, A., André, J. B., \& Bredeche, N. (2016). To cooperate or not to cooperate: Why behavioural mechanisms matter. PLoS Computational Biology, 12, e1004886.

Boesch, C., \& Boesch, H. (1989). Hunting behavior of wild chimpanzees in the Taï National Park. American Journal of Physical Anthropology, 78, 547-573.

Bowen, W. D. (1981). Variation in coyote social organization: The influence of prey size. Canadian Journal of Zoology, 59, 639-652.

Bowman, R. (2003). Apparent cooperative hunting in Florida scrub-jays. Wilson Bulletin, 115, 197-6199.

Bshary, R., Hohner, A., Ait-El-Djoudi, K., \& Fricke, H. (2006). Interspecific communicative and coordinated hunting between groupers and giant moray eels in the Red Sea. PLoS Biology, 4, e431. doi: 10.1371/journal.pbio.0040431

Cott, H. B. (1961). Scientific results of an inquiry into the ecology and economic status of the Nile crocodile (Crocodilus niloticus) in Uganda and Northern Rhodesia. The Transactions of the Zoological Society of London, 29, 211-356.

Creel, S., \& Creel, N. M. (1995). Communal hunting and pack size in African wild dogs, Lycaon pictus. Animal Behaviour, 50, 1325-1339.

Dinets, V. (2015). Apparent coordination and collaboration in cooperatively hunting crocodilians. Ethology Ecology and Evolution, 27, 244-250.

Doody, J. S., Burghardt, G. M., \& Dinets, V. (in press). Reptile social behavior. Baltimore, MD: John Hopkins University Press.

Doody, J. S., Burghardt, G. M., \& Dinets, V. (2013). Breaking the social-nonsocial dichotomy: A role for reptiles in vertebrate social behaviour research? Ethology, 118, 1-9.

Eaton, R. L. (2009). Cooperative hunting by cheetahs and jackals and a theory of domestication of the dog. Mammalia, 33, 87-92.

Gazda, S. K., Connor, R. C., Edgar, R. K., \& Cox, F. (2005). A division of labour with role specialization in group-hunting bottlenose dolphins (Tursiops truncatus) off Cedar Key, Florida. Proceedings of the Royal Society B, Biological Sciences, 272, 135-140. 
James, M., \& Fox, T. (2007). The largest of lizards. The newsletter of the Gippsland Plains Conservation Management Network, 1, 1-9.

Hardy, J. D. (1957). Bat predation by the Cuban boa, Epicrates angulifer Bibron. Copeia, 1957, 151-152.

Herbert-Read, J. E., Romanczuk, P., Krause, S., Strömbom, D., Couillaud, P., Domenici, P., . . Krause, J., (2016). Proto-cooperation: Group hunting sailfish improve hunting success by alternating attacks on grouping prey. Proceedings of the Royal Society. Advance online publication. arXiv preprint arXiv:1603.00869.

Horn, H. G. (1999). Evolutionary efficiency and success in monitors: A survey of behavior and behavioral strategies. Mertensiella, 11, 167-180.

Hyodo, D., Himuro, C., \& Fujisaki, K. (2014). Prey size affects the costs and benefits of group predation in nymphs of the predatory stink bug Andrallus spinidens (Heteroptera: Pentatomidae). Journal of Ethology, 32, 173 178.

Leonardi, G. (1999). Cooperative hunting of the Jackdaws by the Lanner Falcon (Falco biarmicus). Journal of Raptor Research, 33, 123-137.

Lioni, A., Sauwens, C., Theraulaz, G., \& Deneubourg, J. L. (2001). Chain formation in Oecophylla longinoda. Journal of Insect Behavior, 14, 679-696.

Lönnstedt, O. M., Ferrari M. C. O., \& Chivers, D. P. (2014). Lionfish predators use flared fin displays to initiate cooperative hunting. Biology Letters, 10, 20140281.

Mech, L. D. (2007). Possible use of foresight, understanding, and planning by wolves hunting muskoxen. Arctic, 60, $145-149$.

Mech, L. D., \& Boitani, L. (2003). Wolves: Behavior, ecology, and conservation. Chicago, IL: University of Chicago Press.

Nedyalkov, A. G. (1967). Lovtsy Zmei [Snake Hunters]. Moscow: Znanie (in Russian).

Pinheiro, J., Bates, D., DebRoy, S., Sarkar, D., \& R Core Team (2016, May 10). nlme: Linear and Nonlinear Mixed Effects Models. R package version 3.1-128. Retrieved from http://CRAN.R-project.org/package=nlme.

Pitman, C. R. S. (1931). A game warden among his charges. London: Nisbet.

R Core Team (2016, June 16). R: A language and environment for statistical computing. R Foundation for Statistical Computing, Vienna, Austria. Retrieved from https://www.R-project.org/.

Rodriguez, G., \& Reagan, G. P. (1984). Bat predation by the Puerto Rican boa (Epicrates inornatus). Copeia, 1984, 219-220.

Smith, T. G., Siniff, D. B., Reichle, R., \& Stone, S. (1981). Coordinated behavior of killer whales, Orcinus orca, hunting a crabeater seal, Lobodon carcinophagus. Canadian Journal of Zoology, 59, 1185-1189.

Stander, P. E. (1992). Cooperative hunting in lions: The role of the individual. Behavioral Ecology and Sociobiology, 29, 445-454.

Stiner, M., Barkai, R., \& Gopher, A. (2009). Cooperative hunting and meat sharing 400-200 kya at Qesem Cave, Israel. Proceedings of the National Academy of Sciences, 106, 13207-13212.

Yosef, R., \& Yosef, N. (2010). Cooperative hunting in brown-necked raven (Corvus rufficollis) on Egyptian Mastigure (Uromastyx aegyptius). Ethology, 28, 385-388. 